\title{
20. správa Faunistickej komisie Slovenskej ornitologickej spoločnosti/BirdLife Slovensko
}

\author{
The $20^{\text {th }}$ report of the Rarities Committee \\ of the Slovak Ornithological Society/BirdLife Slovakia
}

\section{Richard KvetKo ${ }^{1}$, Marian MoJžıš ${ }^{2}$, Stanislav Harvančí ${ }^{3}$, Dušan Karaska ${ }^{4}$, Milan OLEKŠÁK ${ }^{5}$, Vladimír ŠRANK ${ }^{6}$ \& Rudolf JUREČEK ${ }^{7}$}

\author{
${ }^{1}$ SNP 14, 90301 Senec, Slovensko; e-mail: richard.kvetko@centrum.sk \\ ${ }^{2}$ Školská 211/22, 98531 Mučín, Slovensko \\ ${ }^{3}$ Pod Šípkom 1153 /1, 95806 Partizánske, Slovensko \\ ${ }^{4} 02741$ Oravský Podzámok 261, Slovensko \\ ${ }^{5}$ Správa NP Slovenský kras, Hámosiho 188, 04951 Brzotín, Slovensko \\ ${ }^{6}$ Ul. SNP 19/3, 97201 Bojnice, Slovensko \\ ${ }^{7}$ Správa CHKO Záhorie, Vajanského 11, 90101 Malacky,Slovensko
}

\begin{abstract}
In 2019, the Rarities Committee of the Slovak Ornithological Society/BirdLife Slovakia reviewed 34 records, of which 22 were accepted in the category $A$ and four in category $C$. Furthermore, seven breeding records were accepted. First record of the Rustic Bunting (Emberiza rustica), one record of the Brant Goose (Branta bernicla), one record of the Lesser White-fronted Goose (Anser erythropus), two records of the Red-breasted Goose (Branta ruficollis), one record of the Common Chiffchaff (Phylloscopus collybita tristis type) and two records of the Yellow-browed Warbler (Phylloscopus inornatus) were the most interesting records in 2019. Rarities Committee accepted observations from the year 2019, but also some valuable observations from years 2015 and 2018. For example four records of the Egyptian Goose (Alopochen aegyptiaca), two records of the Glossy Ibis (Plegadis falcinellus), three breeding records of the Common Merganser (Mergus merganser), two breeding records of the Egyptian Goose (A. aegyptiaca), some breeding records of the Red-crested Pochard (Netta rufina), first breeding record of the Whooper Swan (Cygnus cygnus), two records of the Horned Grebe (Podiceps auritus), one record of the Pallid Harrier (Circus macrourus), one record of the Eurasian Dotterel (Charadrius morinellus), one record of the Greater Spotted Eagle (Clanga clanga), two records of the European Herring Gull (Larus argentatus), one record of the Black-legged Kittiwake (Rissa tridactyla), one record of the European Roller (Coracias garrulus), one record of the Citrine wagtail (Motacilla citreola), one record of Pratincole species (Glareola sp.) and one record of the Lapland Longspur (Calcarius lapponicus).
\end{abstract}

Keywords: birds, rarities committee, rarities report, Slovakia

\section{Úvod}

V tomto príspevku je prezentovaná správa z činnosti Faunistickej komisie (FK) za rok 2019. Faunistická komisia pracovala v roku 2019 v nasledovnom zložení: Richard Kvetko predseda, Stanislav Harvančík, Rudolf Jureček,
Dušan Karaska, Marian Mojžiš, Milan Olekšák a Vladimír Šrank - členovia.

Spolu bolo prejednaných 34 hlásení za rok 2019, z ktorých bolo 22 pozorovaní akceptovaných v kategórii A a štyri pozorovania v kategórii C. Okrem týchto pozorovaní FK akceptovala sedem hniezdení štyroch druhov. V prípade 
jedného pozorovania zatial' FK nerozhodla. FK posudzovala okrem pozorovaní z r. 2019 aj niektoré staršie údaje.

Prehl'ad akceptovaných pozorovaní je uvedený nižšie v nasledujúcej forme: druh (poddruh), lokalita, dátum, počet jedincov, prípadne vek a pohlavie, pozorovatel', číslo rozhodnutia FK, druh dokladu. Čísla v zátvorkách za názvom taxónu pri akceptovaných hláseniach znamenajú sumár doterajších akceptovaných pozorovaní na území SR do 31. 12. 2019. Počet pozorovaní a počet pozorovaných jedincov je oddelený lomítkom. Kombinácia čísiel pri počte pozorovaní vo forme napr. $\mathrm{n}+2$ znamená, že okrem dvoch akceptovaných pozorovaní existujú d’alšie pozorovania, ktoré FK zatial' neprejednávala prípadne sú v procese posudzovania. Nakol'ko spracovanie množstva údajov z predchádzajúcich rokov na nás čaká v blízkej budúcnosti, niektoré údaje nie sú vždy uvedené (napr. počet pozorovaných jedincov).

FK prijala uznesenie, na základe ktorého sa bude na Slovensku od 1. 1. 2020 používat' taxonómia podl'a IOC (Gill et al. 2020). Aktuálny zoznam druhov bude prístupný na stránkach Slovenskej ornitologickej spoločnosti/BirdLife Slovensko.

Ornitológovia, ktorí disponujú pozorovaním druhu podliehajúceho hláseniu, by mali vyplnit' formulár (pokial' je to možné v elektronickej forme) dostupný na stránke SOS/BirdLife Slovensko (http://www.vtaky.sk/stranka/50Faunisticka-komisia.html) a zaslat' ho na FK (fksosbirdlife@gmail.com), prípadne použili elektronický formulár na stránke Aves symfony (http://aves.vtaky.sk). V súlade s medzinárodnými pravidlami platí, že pozorovanie, ktoré neprešlo schval'ovaním FK, prípadne bolo zamietnuté, sa nesmie používat' v odbornej alebo vedeckej publikácii. Upozorňujeme, že na základe odporúčania AERC (Association of European Rarities Committees, http://www. aerc.eu) je žiadúce prvé pozorovanie (lepšie však prvých 5) s jeho podrobným popisom publikovat' $\mathrm{v}$ národnom (nie regionálnom) periodiku, spolu s cudzojazyčným (anglicky, nemecky) súhrnom.
V prípade, že akceptované pozorovanie publikované $\mathrm{v}$ tejto alebo predchádzajúcich správach zatial' nebolo inde uverejnené, teda nie je k dispozícii iný citačný zdroj, pri citovaní jednotlivých pozorovaní sa odporúča uviest' aj meno pozorovatel'a, napr. „čajka morská (Larus marinus) 24. 10. 2010 Žilina, Váh, 1 subadult (Kizek in Kvetko \& Šrank 2012)“".

Nad'alej platí, že pri označovaní pozorovatel'ov sa uvádzajú mená tých, ktorí ako prví pozorovali a určili vtáka. Ak pozorovali vtáka zároveň aj d'alšie osoby, postupuje sa nasledovne: pri počte 1 až 3 pozorovatel'ov sa vymenujú všetci pozorovatelia; pri vyššom počte ako 3 pozorovatelia sa uvedie len meno pozorovatel'a vo forme napr. „Karaska a kolektív“. Ak bol vták pozorovaný počas viacerých dní aj inými pozorovatel'mi, uvedie sa pozorovanie vo forme napr. „Karaska a iní“.

\section{Akceptované hlásenia (Accepted records)}

Overované druhy boli zaradené do jednotlivých kategórií podla princípov AERC:

Kategória A - Taxóny zaznamenané na území terajšej Slovenskej republiky aspoň raz od 1. 1. 1950 a s najväčšou pravdepodobnost'ou pochádzajúce z prirodzenej populácie.

Kategória B - Taxóny zaznamenané na území terajšej Slovenskej republiky aspoň raz v období medzi 1. 1. 1800 až 31. 12. 1949 a s najväčšou pravdepodobnost'ou pochádzajú $\mathrm{z}$ prirodzenej populácie.

Kategória C - Introdukované taxóny, ktoré na území Slovenskej republiky vytvárajú samostatne sa udržiavajúce hniezdne populácie, alebo k nám zaletujú z takýchto populácií v zahraničí.

Kategória D - Taxóny vyskytujúce sa na území Slovenskej republiky, pri ktorých sú pochybnosti o ich prirodzenom pôvode.

Kategória E - Taxóny vyskytujúce sa na území Slovenskej republiky, pričom s najväčšou pravdepodobnost'ou alebo s určitost'ou možno vylúčit' ich prirodzený pôvod (patria sem predovšetkým úniky zo zajatia). 


\section{Kategória A}

\section{Branta bernicla}

16. 1. - 18. 1. 2019, 1ex., Zohor, Lósy, Vel'ké Leváre; Richard Schnürmacher, Tomáš Tedla a iní; FK 3/2019, foto (obr. 1).

\section{Branta ruficollis}

19. 2. 2019, 1ex., Šamorín, Hrušovská zdrž, Andrej Chudý; FK 5/2019, foto.

8. 11. 2019, 1 ex., Mikušovce; Marian Mojžiš;

FK 28/2019, foto.

\section{Anser erythropus}

16. 1. - 17. 1. 2019, 1ex., Zohor, Lósy a Jakubov; Richard Schnürmacher, Miloslav Mišík, Ján Svetlík a iní; FK 2/2019, foto

8. 2. 2019, 1 ex., Jakubov, Rudolf Jureček, Tomáš Tedla.

\section{Podiceps auritus}

11. 11. 2018, 1 ex., Budmerice, Hájiček, Pavol Valachovič; FK 16/2019.

19. 2. 2019, 1 ex., Šamorín, Hrušovská zdrž, Andrej Chudý, Štefan Benko; FK 4/2019.

Potápka ušatá sa každoročne pozoruje na väčších vodných plochách počas jarnej a jesennej migrácie. Jej výskyt je pravdepodobne vyšší, pre nedostatočnú siet' pozorovatel'ov a nenápadnost' však zrejme uniká pozornosti.

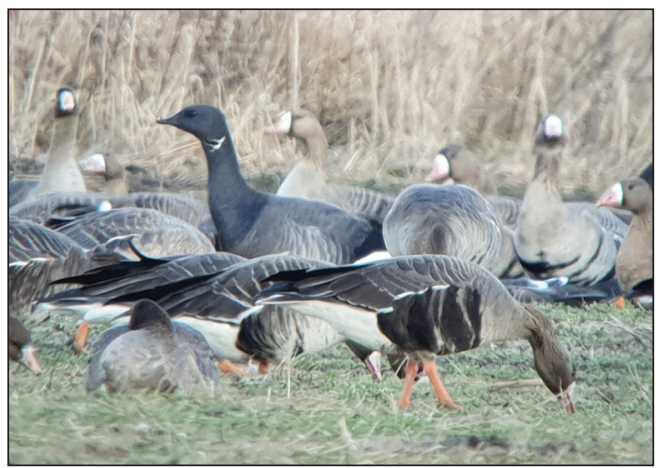

Obr. 1. Bernikla tmavá (Branta bernicla), Vel'ké Leváre, 18. 1. 2019 (Foto: T. Tedla).

Fig. 1. Brant Goose (Branta bernicla), Velké Leváre, January 18, 2019 (Photo by T. Tedla).

\section{Charadrius morinellus}

24. 9. 2019, 1 ex., Mikušovce, Marian Mojžiš; FK 27/2019.

Kulík vrchovský patrí medzi pravidelné a málopočetné transmigranty. Druh je na Slovensku najčastejšie pozorovaný najmä počas jesennej migrácie v kotlinách severného a stredného Slovenska.

\section{Glareola sp.}

16. 10. 2018, 1 ex., Dolný Štál, Hroboňovské rybníky, Kristián Bacsa, Roman Slobodník; FK 17/2019.

\section{Riss a tridactyla}

24. 11. - 27. 11. 2019, 1 ad., Jakubov, Jakubovské rybníky, Ivana Moncmanová, Peter Orság a iní; FK 24/2019, foto (obr. 2).

\section{Larus argentatus}

8. 12. 2019, 2 ex. (1 ad., 1 juv.), Kalinkovo, VD Gabčíkovo, Kalinkovská zátoka, Miloslav Mišík, Martin Mišík; FK 25/2019, foto.

14. 12. 2019, 2 ex. (1 ex. v 3. kalendárnom roku života, 1 juv.), Senec, Slnečné jazerá, Miloslav Mišík, Emília Mišíková Elexová, Martin Mišík; FK 26/2019, foto.

Čajku striebristú môžeme na Slovensku pozorovat' $\mathrm{v}$ malých počtoch $\mathrm{v}$ kŕdl'och iných druhov vel'kých čajok počas migrácie a zimovania. Druh bol najčastejšie registrovaný v západnej časti Slovenska, v okolí vodných

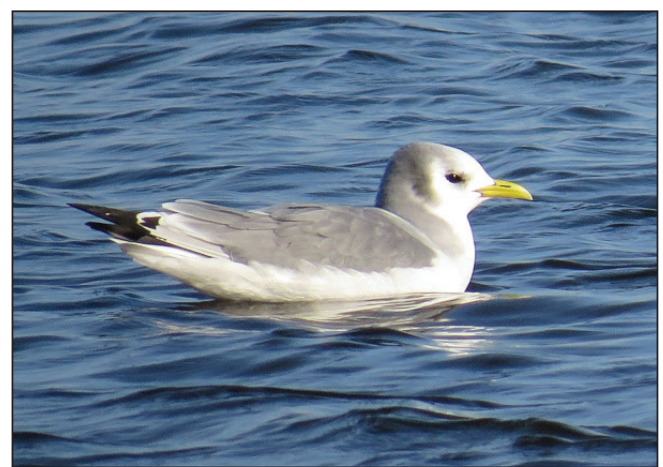

Obr. 2. Čajka trojprstá (Rissa tridactyla), Jakubov, Jakubovské rybníky, 24. 11. 2019 (Foto: P. Orság).

Fig. 2. Black-legged Kittiwake (Rissa tridactyla), Jakubov, Jakubov fishponds, November 24, 2019 (Photo by P. Orság). 


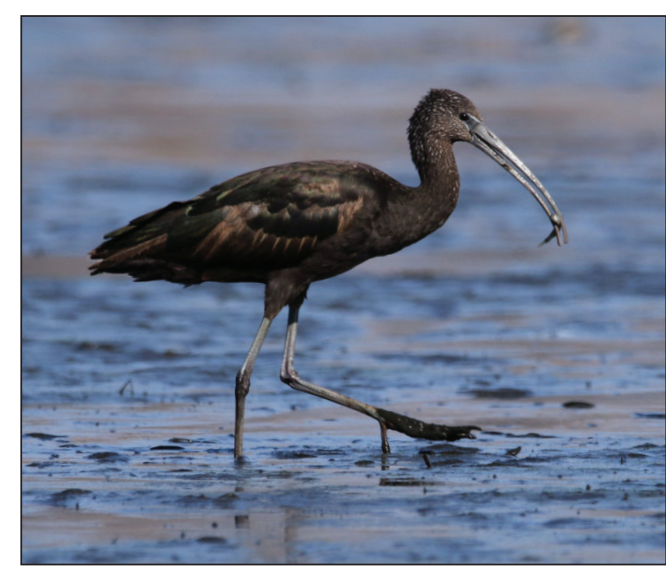

Obr. 3. Ibisovec hnedý (Plegadis falcinellus), Plavecký Štvrtok, Jakubov, 20. 3. 2019 (Foto: J. Dobšovič).

Fig. 3. Glossy Ibis (Plegadis falcinellus), Plavecký Štvrtok, Jakubov, March 20, 2019 (Photo by J. Dobšovič).

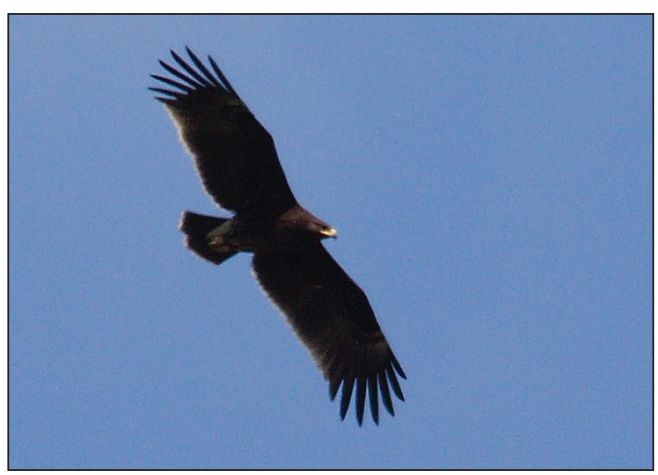

Obr. 4. Orol hrubozobý (Clanga clanga), Iňačovce, 18. 4. 2019 (Foto: E. Hrtan).

Fig. 4. Greater Spotted Eagle (Clanga clanga), Iňačovce, April 18, 2019 (Photo by E. Hrtan)

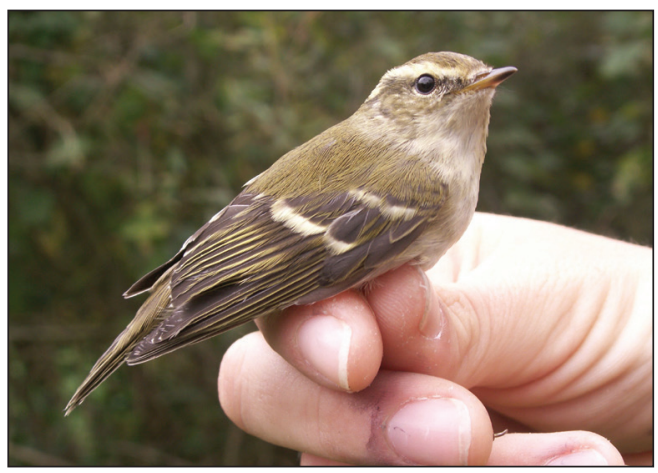

Obr. 5.Kolibiarik žltkastotemenný (Phylloscopus inornatus), Drienovec, Drienovská mokrad', 4. 10. 2019 (Foto: P. Ďurian). Fig. 5. Yellow-browed Warbler (Phylloscopus inornatus), Drienovec, Drienovská mokrad', October 4, 2019 (Photo by P. Durian) tokov a skládok komunálneho odpadu (Kvetko \& FK SOS/BirdLife Slovensko 2015, 2016, 2017).

\section{Plegadis falcinellus}

17. 3. - 20. 3. 2019, 1ex., Plavecký Štvrtok, Jakubov, Jakubovské rybníky; Daniel Petrakovič, Richard Schnürmacher a iní; FK 22/2019, foto (obr. 3).

30. 4. 2019, 1 ex., Iňačovce; Marian Mojžiš, Dušan Kerestúr; FK 19/2019.

\section{Clanga clanga}

18. 4. 2019, 1 ex. v druhom roku života, Iňačovce, NPR Senianske rybníky; Ervín Hrtan a kolektív; FK 14/2019, foto (obr. 4).

\section{Circus macrourus}

24. 4. 2019, 1 ad. samec, Kaplna, agrocenózy, Štefan Granec; FK 12/2019, foto.

Kaňa stepná je každoročný ale málopočetný transmigrant. Najčastejšie bola pozorovaná počas jarného a jesenného t'ahu (Kvetko \& FK SOS/BirdLife Slovensko 2014, 2018).

\section{Coracias garrulus}

18. 6. 2019, 2 ex., Strážne, Vel'ký Kamenec, Peter Chrašč; FK 29/2019.

Po poslednom dokázanom zahniezdení krakle belasej na Slovensku (Bohuš 2010) sa druh sporadicky objavuje aj v hniezdnom období, predovšetkým na juhu a východe Slovenska (Kvetko \& FK SOS/BirdLife Slovensko 2017), kde sa očakáva aj zahniezdenie druhu.

\section{Phylloscopus inornatus (12/12)}

4. 10. 2019, 1 ex., Drienovec, ornitologický stacionár Drienovská mokrad', Tímea Horváthová, Peter Ďurian, Monika Gálffyová a kolektív; FK 18/2019, foto (obr. 5).

7. 10. 2019, 1 ex. v prvom kalendárnom roku života, Koš, Sebedražie, Roman Slobodník, Vladimír Slobodník; FK 20/2019, foto.

Kolibiarik žltkastotemenný patrí na Slovensku medzi vzácne zatúlance. Odchytené jedince sú jedenástym a dvanástym potvrdeným výskytom druhu na Slovensku (Kvetko, 
Mojžiš, Harvančík, Karaska, Olekšák, Šrank \& Jureček 2019).

Phylloscopus collybita typ ,tristis “

13. 12. 2015, 1 ex., Lučenec, močiar pri Béteri, Dušan Kerestúr; FK 13/2019, foto (obr. 6).

\section{Motacilla citreola}

21. 4. 2019, 1 ex, Lukáčovce, Lukáčovské rybníky, Ivana Moncmanová, Peter Orság, L'ubomír Moncman; FK 23/2019, foto.

\section{Calcarius lapponicus}

10. - 11. 1. 2019, 5 ex., Hamuliakovo, VD Gabčíkovo, medzihrádzový priestor, Štefan Brunczlík, Richard Schnürmacher a kolektív; FK 1/2019, foto (obr. 7).

\section{Emberiza rustica (1/1)}

1. 10. 2019, 1 ex., Nový Ruskov, VN Malý Ruskov, Pavol Kočar; FK 34/2019, foto (obr. 8).

Jedná sa o prvý dokumentovaný záznam tohto severského druhu.

\section{Kategória C}

Alopochen aegyptiaca $(\mathrm{n}+25)$

31. 12. 2018, 9 ex., Smolenice, VN Boleráz,

Ivana Moncmanová, L’ubomír Moncman; FK 11/2019, foto.

2. 2. 2019, 3 ex., Tvrdošovce, Dlhý kanál, Jozef Lengyel; FK 21/2019.

4. 5. 2019, 1ex., Zemianske Š́rovce, štrkovňa Súrovce, Peter Orság, Zuzana Lackovičová; FK 7/2019, foto.

29. 4. 2019, 1ex., Slanica, Oravská priehrada,

Vtáčí ostrov, Miroslav Demko; FK 8/2019.

\section{Hniezdenie / Breeding}

\section{Cygnus cygnus}

5. 4. - 6. 8. 2019, 4 ex. (2 ad., 2 nelietajúce juv.), Glabušovce, vodná nádrž, Marian Mojžiš, Dušan Kerestúr; FK 15/2019, foto (obr. 9).

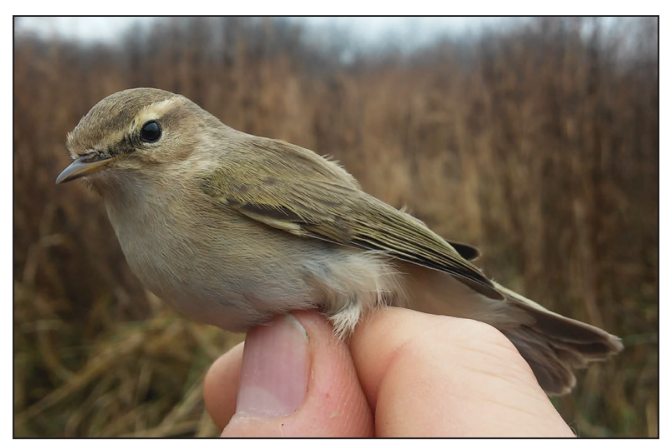

Obr. 6. Kolibiarik čipčavý typ „tristis“(Phylloscopus collybita typ „tristis“), Lučenec, močiar pri Béteri, 13. 12. 2015 (Foto: D. Kerestúr).

Fig. 6. Common Chiffchaff "tristis" type (Phylloscopus collybita „tristis“ type), Lučenec, December 13, 2015 (Photo by D. Kerestúr).

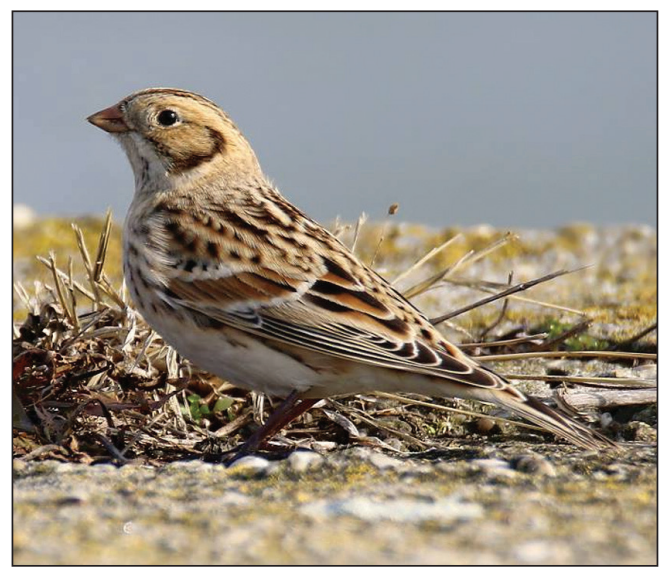

Obr. 7. Ostrohárka severská (Calcarius lapponicus), Hamuliakovo, VD Gabčíkovo, 10. 1. 2019 (Foto: Š. Brunczlík). Fig. 7. Lapland Longspur (Calcarius lapponicus), Hamuliakovo, VD Gabčíkovo, January 10, 2019 (Photo by Š. Brunczlík).

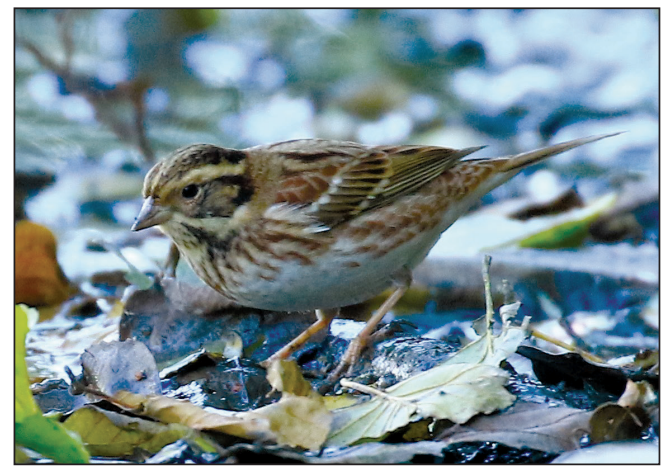

Obr. 8. Strnádka rol'ná (Emberiza rustica), Nový Ruskov, 1. 10. 2019 (Foto: P. Kočar).

Fig. 8. Rustic Bunting (Emberiza rustica), Nový Ruskov, October 1, 2019 (Photo by P. Kočar). 


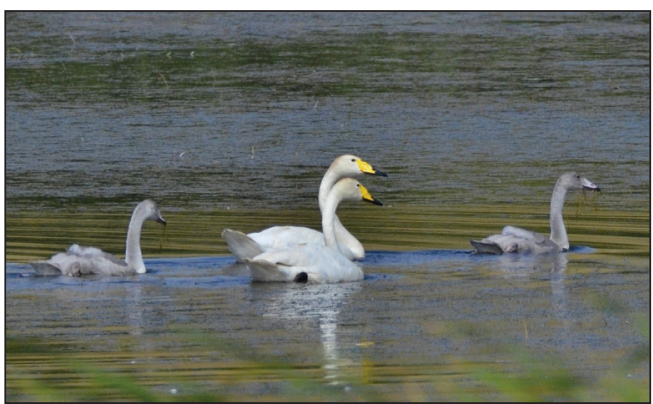

Obr. 9. Labut' spevavá (Cygnus cygnus), Glabušovce, vodná nádrž, 2. 7. 2019 (Foto: M. Mojžiš).

Fig. 9. Whooper Swan (Cygnus cygnus), Glabušovce, water reservoir, July 2, 2019 (Photo by M. Mojžiš).

Jedná sa o prvé zahniezdenie druhu na Slovensku (Mojžiš \& Kerestúr 2019). V blízkom okolí, na mad'arskom území Poiplia hniezdi labut' spevavá od roku 2005 (Selmeczi 2005, MME 2008).

\section{Alopochen aegyptiaca}

12. 7. - 15. 7. 2019, 8 ex. (2 ad., 6 pulli), Bratislava, Nové mesto, Kuchajda, Samuel Pačenovský; FK 9/2019, foto.

20. 7. 2019, 5 ex. (2 ad., 3 pulli), Budmerice, Hájiček, Štefan Granec; FK 10/2019, foto.

\section{Netta rufina}

17. 7. 2019, 18 ex. (7 ad., 11 pulli), BratislavaPodunajské Biskupice, Kalinkovo, severný priesakový kanál, Samuel Pačenovský; FK 30/2019.

\section{Mergus merganser}

10. 6. 2019, 11 ex. (1 ad. samica, 10 nelietajúcich juv.), Želiezovce, Hron, Terézia Jauschová, Peter Zach; FK 31/2019, foto.

10. 6. 2019, 12 ex. (1 ad. samica, 11 nelietajúcich juv.), Vozokany nad Hronom, Hron, Terézia Jauschová, Peter Zach; FK 32/2019, foto.

8. 7. 2019, 4 ex. (1 ad. samica, 3 nelietajúce juv.), Udavské, Vel'opolie, Laborec, Štefan Mikiara; FK 33/2019.

Pri prvých dvoch pozorovaniach sa nedá vylúčit', že sa jedná o totožné jedince.

\section{Literatúra}

BoHUš M. 2011: Hniezdenie a výskyt krakle belasej (Coracias garrulus) na juhozápadnom Slovensku v rokoch 2007-2011. - Tichodroma 23: 13-20.

Gill F., Donsker D. \& Rasmussen P. (Eds). 2020. IOC World Bird List (v10.2). doi: 10.14344/IOC.ML.10.2.

KvetKo R. \& FK SOS/BirdLife SLOvensko 2014: 14. správa Faunistickej komisie Slovenskej ornitologickej spoločnosti/BirdLife Slovensko. - Tichodroma 26: 97-106.

KvetKo R. \& FK SOS/BiRdLIFE SLOVENSKo 2015: 15. správa Faunistickej komisie Slovenskej ornitologickej spoločnosti/BirdLife Slovensko. — Tichodroma 27: 128-135.

KvetKo R. \& FK SOS/BiRdLifE SLOVENSKo 2016: 16. správa Faunistickej komisie Slovenskej ornitologickej spoločnosti/BirdLife Slovensko. — Tichodroma 28: 106-113.

KvetKo R. \& FK SOS/BirdLifE SLOvensKo 2017: 17. správa Faunistickej komisie Slovenskej ornitologickej spoločnosti/BirdLife Slovensko. — Tichodroma 29: 42-48.

KvetKo R. \& FK SOS/BirdLifE SLOvensKo 2018: 18. správa Faunistickej komisie Slovenskej ornitologickej spoločnosti/BirdLife Slovensko. - Tichodroma 30: 80-87.

Kvetko R., Mojžiš M., Harvančík S., Karaska D., OleKšÁK M., ŠrANK V. \& JUREČEK R. 2019: 19. správa Faunistickej komisie Slovenskej ornitologickej spoločnosti/BirdLife Slovensko. - Tichodroma 31: 49-55.

MME Nomenclator Bizottság 2008: Magyarország madarainak névjegyzéke. Nomenclator avium Hungariae. - Magyar Madártani és Természetvédelmi Egyesület, Budapest. 278 p.

Mojžiš M. \& Kerestúr D. 2019: Prvé hniezdenie labute spevavej (Cygnus cygnus) na Slovensku. - Tichodroma 31: 19-23.

Selmeczi KovÁcs Á. 2005: Újra fészkel Magyarországon az énekes hattyú. — Madártávlat 12 (4): 10.

Received: 28. 12. 2020

Accepted: 29. 12. 2020

Online: 28. 2. 2021 